\title{
Preoperative anemia and transfusion in cardiac surgery: a single-centre retrospective study
}

\author{
Quynh Nguyen ${ }^{1}$, Eric Meng ${ }^{2}$, Joel Berube ${ }^{2}$, Richard Bergstrom² and Wing Lam² ${ }^{2}$ (D)
}

\begin{abstract}
Background: Preoperative anemia and transfusion are associated with worse outcomes. This study aims to identify the prevalence of preoperative anemia, transfusion rates on surgery day, and predictors of transfusion in elective cardiac surgery patients at our centre. We also aim to evaluate our preoperative intervention program, and examine the intervention window for anemia before surgery.

Methods: This study included 797 adult patients who underwent elective cardiac surgery at a tertiary hospital. Multivariable logistic regression analysis was used to identify predictors of transfusion on surgery day.

Results: Preoperative anemia was present in $15 \%$ of patients. Anemic patients had a significantly higher transfusion rate at 53\% compared to $10 \%$ in non-anemic patients. Hemoglobin concentration, estimated glomerular filtration rate (eGFR), body surface area (BSA), and total cardiopulmonary bypass time were predictive of transfusion on surgery day. Patients had a median of 7 days between initial visit and surgery day, however, referral to the blood conservation clinic was only done for $8 \%$ of anemic patients and treatment was initiated in $3 \%$ of anemic patients. Among the 3 anemic patients who received treatment, 2 did not require blood transfusion on surgery day.

Conclusions: Preoperative anemia is present in 15\% of patients at our centre and these patients have 53\% transfusion rates on surgery day. Hemoglobin concentration, eGFR, BSA, and total cardiopulmonary bypass time were predictors of transfusion on surgery day. Patients had a median of 7 days between initial visit and surgery day. Referral and anemia treatment were infrequently initiated in preoperative anemic patient.
\end{abstract}

Keywords: Pre-operative anemia, Transfusion, Cardiac surgery

\section{Background}

Anemia is common in patients undergoing surgery, especially in cardiac surgery $[1,2]$. The prevalence of preoperative anemia among patients undergoing cardiac surgery is highly variable, depending on the definition of anemia used across studies as well as centre-specific

\footnotetext{
* Correspondence: wingying@ualberta.ca

${ }^{2}$ Division of Anesthesiology \& Pain Medicine, Department of Medicine, Faculty of Medicine and Dentistry, University of Alberta, Edmonton, Alberta T6G 2S2, Canada

Full list of author information is available at the end of the article
}

patient populations. Using the World Health Organization (WHO) definition, the general consensus for preoperative anemia prevalence is around $20-30 \%$ and increases with age and the presence of comorbidities $[2,3]$. The most common causes of preoperative anemia in cardiac surgery patients are hospital-acquired anemia, iron-deficiency anemia, and anemia of chronic disease $[4,5]$. The risk of anemia is exacerbated in cardiac surgery patients due to acute hemodilution associated with cardiopulmonary bypass (CPB), perioperative phlebotomy, and surgical blood loss [6]. Preoperative anemia is associated with higher morbidity and mortality, longer 
intensive care unit (ICU) and hospital stays, and increased health care costs $[2,4,7,8]$.

Preoperative anemia also increases perioperative red blood cell (RBC) transfusion rates in cardiac surgery patients [1, 9]. Allogeneic blood transfusions are a scarce and costly resource that carry with them significant risks including transfusion reactions, transfusion-related immunomodulation, infectious complications, and other systemic adverse effects [1,9-11]. Similar to preoperative anemia, blood transfusion in cardiac surgery is associated with increased morbidity and mortality, lengths of hospital stay, and health care costs $[2,9]$. The relative contribution of preoperative anemia and RBC transfusion to the adverse outcomes in cardiac surgery patients remains uncertain, however, it has been shown that the interaction of the two increases morbidity and mortality far greater than the additive effects of each exposure individually $[10,12-14]$. Recognizing the implications of preoperative anemia and perioperative transfusion, interventions to improve the hemodynamic status of patients before surgery have been implemented in multiple centres [15]. These blood conservation programs have been shown to decrease transfusion rates, improve outcomes and reduce associated costs $[2,15]$. Preoperative correction of anemia is an essential part of the blood management concept, and is recommended by major professional societies of cardiothoracic surgeons and anaesthesiologists [16-18].

Our study aims to determine the prevalence of anemia, transfusion rates on surgery day, and predictive factors of transfusion in patients undergoing elective cardiac surgery procedures at our institution. We also aim to evaluate our institution's current preoperative intervention program for anemic patients, and examine the referral window to assess the feasibility of such a program in the cardiac surgery setting.

\section{Methods}

\section{Patients and study design}

The study protocol was reviewed and approved by the Health Research Ethics Board at the University of Alberta, Edmonton, Canada. Due to the retrospective design of the study, individual patient consent was waived. This study included 797 adult ( $>18$ years of age) patients who had elective cardiac surgery requiring $\mathrm{CPB}$ at the Mazankowski Alberta Heart Institute (MAHI), Edmonton, Alberta, Canada from October 2017 to October 2019. Patients were identified from our cardiac preadmission clinic (PAC) records. If a patient underwent more than one cardiac surgery during the study period, only the initial surgery was included in the study. Emergency procedures and transplantation (heart, lung, heart and lung) were excluded from the study because these procedures do not allow for an accurate assessment of time between PAC visit and surgery day for preoperative intervention purposes.

Patient clinical characteristics, surgical characteristics and outcomes were gathered via review of physical charts scanned and uploaded onto electronic databases maintained by Alberta Health Services. Patient demographics, comorbidities, lab values and imaging parameters were based on the latest available information before PAC visits. The patient and surgical characteristics chosen in this study were based on commonly seen comorbidities in cardiac surgery patients as well as established anemia- and transfusion- associated risk factors. Complex surgical procedures were defined as any combined surgery such as concomitant coronary artery bypass graft (CABG) and valve, double valve, or aortic surgeries.

Following the WHO definition [3], anemia was defined as having a hemoglobin $(\mathrm{Hb})$ concentration of less than $120 \mathrm{~g} / \mathrm{L}$ in non-pregnant adult females and less than 130 $\mathrm{g} / \mathrm{L}$ in adult males (Table 1). Further sub-classifications using the WHO criteria were done for mild anemia $(\mathrm{Hb}$ concentration between 110 and $120 \mathrm{~g} / \mathrm{L}$ in females and 110 and $130 \mathrm{~g} / \mathrm{L}$ in males), moderate anemia (Hb concentration between 80 and $110 \mathrm{~g} / \mathrm{L}$ in both sexes), and severe anemia (Hb concentration less than $80 \mathrm{~g} / \mathrm{L}$ in both sexes). $\mathrm{Hb}$ values are used as transfusion triggers at our centre; there is no universal $\mathrm{Hb}$ threshold for transfusion. Patient conditions and comorbidities are taken into consideration, which accounts for a higher $\mathrm{Hb}$ threshold in sicker patients. The general consensus is that otherwise healthy patients with $\mathrm{Hb}>100 \mathrm{~g} / \mathrm{L}$ rarely require perioperative $\mathrm{RBC}$ transfusion, and those with $\mathrm{Hb}<80 \mathrm{~g} / \mathrm{L}$ frequently require $\mathrm{RBC}$ transfusion. For this study, transfusion on surgery day was defined as any packed $\mathrm{RBC}(\mathrm{pRBC})$ transfused in the operating rooms or within $24 \mathrm{~h}$ of arrival at the cardiovascular ICU (CVICU).

Information on patient referral and preoperative treatment for anemia at the local blood conservation clinic was obtained by cross-referencing our patient list with the blood conservation clinic's patient database. Referral criteria for surgical patients are: having a $\mathrm{Hb}$ concentration of $70-130 \mathrm{~g} / \mathrm{L}$ and a ferritin concentration of less than $100 \mathrm{ng} / \mathrm{mL}$. Upon referral, patients are triaged based on their blood work results and the available amount of time prior to their scheduled surgeries. Patients are contacted within a week and treatments are initiated within 1-2 weeks of their referrals. For treatment, patients are given intravenous iron sucrose, $200 \mathrm{mg}$ infused over a minimum of $15 \mathrm{~min} \times 2$ doses, 1 week apart. Unstable cardiac patients are contraindicated for treatment.

\section{Statistical analysis}

Non-parametric continuous variables were expressed as medians with their respective interquartile ranges 
Table 1 Prevalence of anemia among our elective cardiac surgery patients

\begin{tabular}{|c|c|c|c|c|c|}
\hline \multirow{2}{*}{$\begin{array}{l}\text { Anemia } \\
\text { degree }\end{array}$} & \multicolumn{2}{|c|}{ Hemoglobin Concentration (g/L) } & \multicolumn{3}{|c|}{ Prevalence } \\
\hline & Non-Pregnant Female & Male & Female & Male & Total \\
\hline Non-Anemic & $\geq 120$ & $\geq 130$ & 206 & 472 & $678(85)$ \\
\hline Anemia (total) & $<120$ & $<130$ & 56 & 63 & $119(15$ \\
\hline Mild & $110-119$ & $110-129$ & 33 & 47 & $80(67)$ \\
\hline Moderate & $80-109$ & $80-109$ & 22 & 16 & $38(32)$ \\
\hline Severe & $<80$ & $<80$ & 1 & 0 & $1(1)$ \\
\hline
\end{tabular}

(IQRs). Categorical variables were expressed as the total number in each category, and the corresponding percentage of the study population they represented. Twotailed Mann Whitney test and two-sided Fisher's exact test or chi-square test were used for non-parametric continuous and categorical data, respectively. All candidate variables were used for multivariable logistic regression analysis, with transfusion on surgery day as an outcome. Akaike information criterion (AIC) was used to compare models, and the one with the lowest AIC was selected. Area under the receiver operating characteristic curve (AUC) was used to measure modelling accuracy. Results were reported as odd ratios (ORs) with 95\% confidence intervals (CIs). A $p$ value of less than 0.05 was considered significant. All statistical analyses were performed using GraphPad Prism version 8.4.3, GraphPad Software, La Jolla California USA.

\section{Results}

\section{Prevalence of Anemia}

Preoperative anemia was present in 119/797 elective cardiac surgery patients (15\%) (Table 1). Of these anemic patients, $67 \%$ had mild, $32 \%$ had moderate, and $1 \%$ had severe anemia. Among all anemic patients, $47 \%$ were female; in particular, $41 \%$ of mildly anemic patients, $58 \%$ of moderately anemic patients, and the only severely anemic patient were female.

\section{Patient characteristics}

In terms of demographics, anemic patients were significantly older $(p=0.003)$, more likely to be female $(p=$ $0.001)$, had lower body weight $(p=0.002)$, and smaller body surface area (BSA) $(p<0.001)$ than non-anemic patients (Table 2). Among patients who were anemic, those with moderate/severe anemia were significantly more likely to have lower body weight $(p=0.005)$, lower body mass index (BMI) $(p=0.031)$ and smaller BSA $(p=$ 0.006).

There were no differences in the surgical procedures performed between anemic and non-anemic patients, as well as between patients with different degrees of anemia. The majority of patients underwent isolated CABG or isolated valve surgery, followed by aortic surgery, combined $C A B G$ and valve, adult congenital and other surgeries. Both patient groups also had similar frequencies of having a repeat sternotomy or undergoing deep hypothermic circulatory arrest (DHCA) during their surgeries. The cross-clamp time and total bypass time were not significantly different among groups.

Anemic patients were significantly more likely to have diabetes $(p<0.0001)$ or a history of cerebrovascular accident (CVA) $(p=0.030)$. There were no differences regarding these co-morbidities between mild and moderate/severe anemic patients. Laboratory and imaging data showed that anemic patients had significantly lower estimated glomerular filtration rate (eGFR) $(p<$ 0.0001 ) and a higher proportion of these patients had reduced left ventricular ejection fraction (LVEF, LVEF < $50 \%)(p=0.029)$. Compared to mild anemic patients, moderate/severe anemic patients were more likely to have lower eGFR $(p=0.046)$ and reduced $\operatorname{LVEF}(p=$ 0.004) values.

\section{Transfusion rates and outcomes in elective cardiac surgery patients}

Anemic patients had a significantly higher transfusion rate at $53 \%$ compared to $10 \%$ in non-anemic patients $(p<0.0001)$ (Table 3). Among patients with anemia, 79\% of moderate/severe anemic patients and $40 \%$ of mild anemic patient required transfusion $(p<0.0001)$. There were no differences in terms of number of pRBCs transfused across groups. The majority of patients received 1-2 pRBCs on surgery day.

With regards to outcomes, anemic patients had significantly worse outcomes as indicated by longer CVICU stays $(p=0.001)$, longer hospital stays $(p<0.0001)$, and higher incidences of in-hospital mortality $(\mathrm{p}<0.0001)$ compared to non-anemic patients. Patients with preoperative anemia spent a median of 3 days in the CVICU and a median of 10 days in the hospital. The in-hospital mortality rate was $9 \%$ in anemic patients compared to $1 \%$ in non-anemic patients. These outcomes were similar between anemic patients of varying severity.

\section{Predictive factors of transfusion on surgery day in elective cardiac surgery patients}

Multivariate logistic regression analysis of all 797 patients showed that $\mathrm{Hb}$ concentration $(\mathrm{OR}=0.930,95 \%$ 
Table 2 Clinical characteristics of our elective cardiac surgical patients with and without anemia

\begin{tabular}{|c|c|c|c|c|c|c|c|}
\hline Parameters & $\begin{array}{l}\text { Non-Anemic } \\
(N=678)\end{array}$ & $\begin{array}{l}\text { Anemic } \\
(N=119)\end{array}$ & $\begin{array}{l}\text { Total } \\
(N=797)\end{array}$ & $P$ value* & $\begin{array}{l}\text { Mild Anemic } \\
(N=80)\end{array}$ & $\begin{array}{l}\text { Mod/Sev. Anemic } \\
(N=39)\end{array}$ & $P$ valuet \\
\hline \multicolumn{8}{|l|}{ Demographics } \\
\hline Age (yr) & $66(56-73)$ & $69(63-76)$ & $66(56-73)$ & 0.003 & 70 (64-76) & $66(57-73)$ & 0.068 \\
\hline Female & $206(30)$ & $56(47)$ & $262(33)$ & 0.001 & $33(41)$ & $23(59)$ & 0.081 \\
\hline Weight & 85 (73-97) & 79 (68-90) & $83(71-96)$ & 0.002 & $82(72-93)$ & $73(63-84)$ & 0.005 \\
\hline $\mathrm{BMI}(\mathrm{kg} / \mathrm{m} 2)$ & $29(25-33)$ & $29(25-33)$ & $29(25-33)$ & 0.340 & $29(25-34)$ & $28(23-31)$ & 0.031 \\
\hline BSA (m2) & $2.0(1.8-2.2)$ & $1.9(1.7-2.1)$ & $2.0(1.8-2.1)$ & $<0.001$ & $1.9(1.8-2.1)$ & $1.8(1.6-1.9)$ & 0.006 \\
\hline Surgical procedures & & & 0.175 & & & & NA \\
\hline Isolated CABG & $157(23)$ & $34(29)$ & $191(24)$ & & $24(30)$ & $10(26)$ & \\
\hline Isolated valve & $290(43)$ & $55(46)$ & $345(43)$ & & $35(44)$ & $20(51)$ & \\
\hline CABG \& valve & $61(9)$ & $13(11)$ & $74(9)$ & & $7(9)$ & $6(15)$ & \\
\hline Aortic surgery & $96(14)$ & $11(9)$ & $107(13)$ & & $9(11)$ & $2(5)$ & \\
\hline Adult congenital & $48(7)$ & $5(4)$ & $53(7)$ & & $4(5)$ & $1(3)$ & \\
\hline Others & $26(4)$ & $1(1)$ & $27(3)$ & & $1(1)$ & $0(0)$ & \\
\hline \multicolumn{8}{|l|}{ Surgical parameters } \\
\hline Repeat sternotomy & $74(11)$ & $15(13)$ & $89(11)$ & 0.635 & $13(16)$ & $2(5)$ & 0.139 \\
\hline Cross-clamp time (min) & $84(61-110)$ & $77(59-103)$ & $83(61-110)$ & 0.252 & $80(58-106)$ & $76(59-102)$ & 0.777 \\
\hline Total bypass time (min) & $106(80-141)$ & $99(81-136)$ & $104(80-141)$ & 0.455 & $102(80-144)$ & $95(84-127)$ & 0.551 \\
\hline DHCA & $32(5)$ & $6(5)$ & $38(5)$ & 0.817 & $6(8)$ & $0(0)$ & 0.176 \\
\hline \multicolumn{8}{|l|}{ Co-morbidities } \\
\hline Diabetes & $161(24)$ & $58(49)$ & $219(27)$ & $<0.0001$ & $38(48)$ & $20(51)$ & 0.845 \\
\hline CVA & $41(6)$ & $14(12)$ & $55(7)$ & 0.030 & $6(8)$ & $8(21)$ & 0.065 \\
\hline \multicolumn{8}{|l|}{ Lab and imaging parameters } \\
\hline eGFR (ml/min/1.73 m2) & $80(66-92)$ & $60(41-85)$ & $78(63-92)$ & $<0.0001$ & $67(45-85)$ & $56(18-83)$ & 0.046 \\
\hline LVEF (\%) & & & & 0.029 & & & 0.004 \\
\hline$\geq 50$ & $560(83)$ & $92(77)$ & $652(82)$ & & $66(83)$ & $26(67)$ & \\
\hline$<50$ & $95(14)$ & $27(23)$ & $122(15)$ & & $14(18)$ & $13(33)$ & \\
\hline \multicolumn{8}{|l|}{ Preoperative intervention } \\
\hline Referral to BCC & NA & $9(8)$ & NA & NA & $5(6)$ & $4(10)$ & 0.473 \\
\hline Received treatment at BCC & NA & $3(3)$ & NA & NA & $0(0)$ & $3(8)$ & 0.033 \\
\hline Days from PAC to surgery & $7(2-15)$ & $7(2-17)$ & $7(2-15)$ & 0.990 & $7(1-14)$ & $7(2-18)$ & 0.537 \\
\hline
\end{tabular}

$B C C$ blood conservation clinic, $B M I$ body mass index, $B S A$ body surface area, $C A B G$ coronary artery bypass graft, CVA cerebrovascular accident, DHCA deep hypothermic circulatory arrest, eGFR estimated glomerular filtration rate, Hb hemoglobin, LVEF left ventricular ejection fraction, min minute, mod/sev moderate/ severe, $P A C$ pre-admission clinic, $P$ value ${ }^{*} p$ value between anemic and non-anemic groups, $P$ valuet $p$ value between mild anemic and moderate/severe anemic groups, yr year

$\mathrm{CI}=0.912-0.947)$, eGFR $(\mathrm{OR}=0.979,95 \% \mathrm{CI}=0.966-$ 0.992), BSA $(\mathrm{OR}=0.018,95 \% \mathrm{CI}=0.005-0.067)$ and total $\mathrm{CPB}$ time $(\mathrm{OR}=1.013,95 \% \mathrm{CI}=1.008-1.019)$ were predictive of transfusion on surgery day in elective cardiac surgery patients (Table 4). The AUC was 0.8886.

\section{Current preoperative intervention and referral windows} Among anemic patients, 9 patients (8\%) were referred to the blood conservation clinic and 3 patients (3\%) received treatment with iron therapy (Table 2). Among the 9 patients with referrals, 5 were in the mild anemia category and 4 were in the moderate/severe anemia category. All 3 anemic patients who received treatment were from the moderate/severe group; 2 did not require blood transfusion and one received $1 \mathrm{pRBC}$ on surgery day. The most common reasons for not receiving treatment in those who were referred include inadequate time between referral and surgery date, not meeting criteria for treatment, and patient no-shows or appointment cancellations. There were no differences in the frequencies of referral to the blood conservation clinic between patients with different degrees of anemia. Once the referral has been made, only moderate/severe anemic patients were treated in our cohort $(p=0.033)$. In terms 
Table 3 Transfusion rates and outcomes among elective cardiac surgery patients

\begin{tabular}{|c|c|c|c|c|c|c|}
\hline Transfusion & $\begin{array}{l}\text { Non-Anemic } \\
(N=678)\end{array}$ & $\begin{array}{l}\text { Anemic } \\
(N=119)\end{array}$ & $P$ value* & $\begin{array}{l}\text { Mild Anemic } \\
(N=80)\end{array}$ & $\begin{array}{l}\text { Moderate/Severe Anemic } \\
(N=39)\end{array}$ & $P$ valuet \\
\hline Transfusion rate & $65(10)$ & $63(53)$ & $<0.0001$ & $32(40)$ & $31(79)$ & $<0.0001$ \\
\hline pRBC transfused & & & 0.915 & & & NA \\
\hline 1 & $26(40)$ & $26(41)$ & & $13(41)$ & $13(42)$ & \\
\hline 2 & $20(31)$ & $17(27)$ & & $8(25)$ & $9(29)$ & \\
\hline 3 & $6(9)$ & $4(6)$ & & $0(0)$ & $4(13)$ & \\
\hline 4 & $6(9)$ & $8(13)$ & & $6(19)$ & $2(6)$ & \\
\hline$\geq 5$ & $7(11)$ & $8(13)$ & & $5(16)$ & $3(10)$ & \\
\hline \multicolumn{7}{|l|}{ Outcomes } \\
\hline Length of CVICU stay (d) & $2(1-4)$ & $3(1-6)$ & 0.001 & $3(1-6)$ & $3(2-6)$ & 0.611 \\
\hline Length of hospital stay (d) & $7(5-9)$ & $10(6-16)$ & $<0.0001$ & $9(6-16)$ & $10(7-14)$ & 0.319 \\
\hline In-hospital mortality & $8(1)$ & $11(9)$ & $<0.0001$ & $6(8)$ & $5(13)$ & 0.501 \\
\hline
\end{tabular}

CVICU cardiovascular intensive care unit, $d$ day, $p R B C$ packed red blood cells, $P$ value ${ }^{*} p$ value between anemic and non-anemic groups, $P$ valuet $p$ value between mild anemic and moderate/severe anemic groups

of referral windows, the median time from PAC visit to surgery date was 7 days, and there were no significant differences across all groups. The majority of patients (430/797 total patients, 54\%; 66/119 anemic patients, $55 \%)$ had 7 days or less between their PAC visits and surgery dates (Fig. 1).

Table 4 Predictive factors of same day transfusion using multivariable logistic regression analysis for patients undergoing elective cardiac surgery

\begin{tabular}{|c|c|c|c|c|}
\hline \multirow[t]{2}{*}{ Parameters } & \multirow{2}{*}{$\begin{array}{l}\text { Odds } \\
\text { Ratio }\end{array}$} & \multicolumn{2}{|l|}{$95 \% \mathrm{Cl}$} & \multirow[t]{2}{*}{$P$ value } \\
\hline & & Lower & Upper & \\
\hline \multicolumn{5}{|l|}{ Demographics } \\
\hline Age & 1.011 & 0.990 & 1.034 & 0.308 \\
\hline Sex & 0.870 & 0.465 & 1.607 & 0.658 \\
\hline BSA & 0.018 & 0.005 & 0.067 & $<0.0001$ \\
\hline \multicolumn{5}{|l|}{ Surgical parameters } \\
\hline Complex surgical procedures & 1.737 & 0.886 & 3.375 & 0.105 \\
\hline Repeat sternotomy & 1.575 & 0.689 & 3.518 & 0.273 \\
\hline Total bypass time & 1.013 & 1.008 & 1.019 & $<0.0001$ \\
\hline DHCA & 1.022 & 0.355 & 2.841 & 0.967 \\
\hline \multicolumn{5}{|l|}{ Co-morbidities } \\
\hline Diabetes & 1.168 & 0.650 & 2.072 & 0.598 \\
\hline CVA & 1.456 & 0.625 & 3.240 & 0.369 \\
\hline \multicolumn{5}{|l|}{ Lab and imaging parameters } \\
\hline eGFR & 0.979 & 0.966 & 0.992 & 0.002 \\
\hline Reduced LVEF & 1.034 & 0.511 & 2.023 & 0.925 \\
\hline Hemoglobin & 0.930 & 0.912 & 0.947 & $<0.0001$ \\
\hline
\end{tabular}

$B S A$ body surface area, $C l$ confidence interval, CVA cerebrovascular accident, $D H C A$ deep hypothermic circulatory arrest, eGFR estimated glomerular filtration rate, $L V E F$ left ventricular ejection fraction

\section{Discussion}

We found that the prevalence of preoperative anemia in elective cardiac surgery patients at our centre is $15 \%$, and that the majority of anemic patients were classified as having mild or moderate anemia according to the WHO definition. Using an $\mathrm{Hb}$ concentration less than $125 \mathrm{~g} / \mathrm{L}$ as the definition of anemia, a multicentre study found the overall prevalence of preoperative anemia in their cardiac surgery patients to be $26 \%$, with values ranging from $22 \%$ to $30 \%$ at participating hospitals [4]. Another multicentre study identified the prevalence of anemia among cardiac surgery patients to be $31 \%$, with centre-specific prevalence varying from $23 \%$ to $45 \%$ [7]. Other studies revealed differing prevalences of anemia in preoperative cardiac surgery patients, ranging from 15\% to over $54 \%$ depending on the definition of anemia used in each study as well as specific patient population characteristics $[2,6,8,19]$. Since we excluded all emergency and transplant cases from our study, this could explain the lower prevalence of anemia in preoperative cardiac surgery patients at our centre compared to other studies. However, the variation in anemia prevalence across different studies is apparent from the literature, and the exact cause for this is unknown [2, 4, 7]. Further studies are required to elucidate the causes of this variation, as they will be important to guide management as well as preoperative blood conservation strategies.

In terms of transfusion rates, 53\% of our anemic patients and $10 \%$ of our non-anemic patients required pRBC transfusion on the day of surgery. The need for blood transfusion was significantly higher in moderate/ severe anemic patients (79\%) compared to mild anemic patients (40\%). These findings are consistent with previous studies at other centres. Klein et al. found a $64 \%$ transfusion rate in anemic and a 37\% transfusion rate in non-anemic patients across multiple centres [7]. A single 


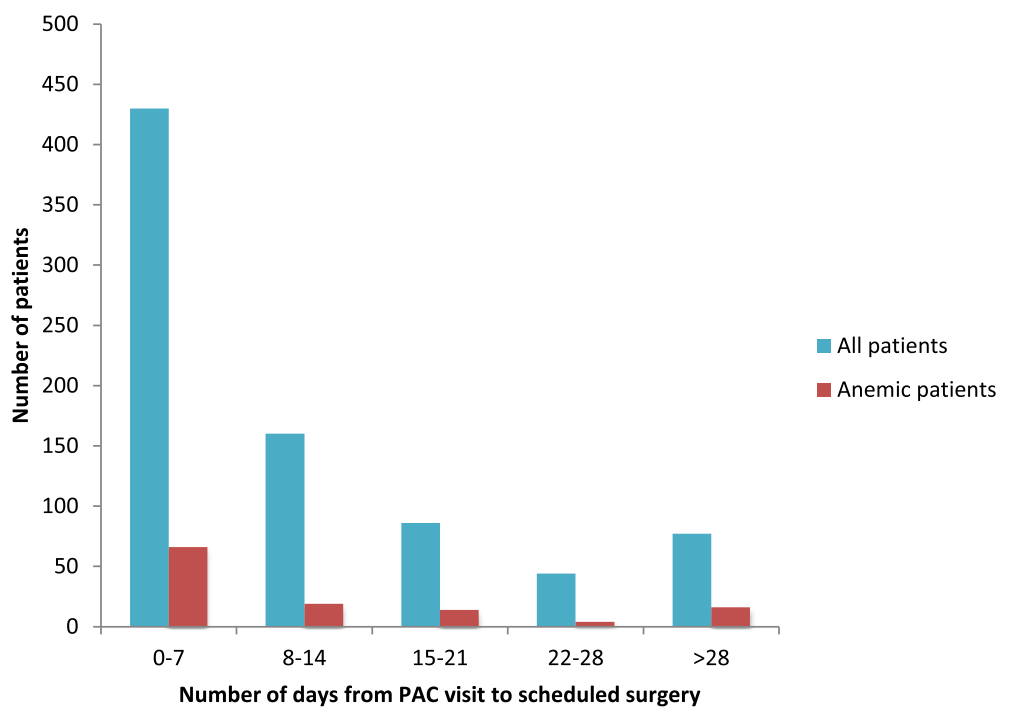

Fig. 1 Number of days from pre-admission clinic visit to scheduled surgery day in all patients $(N=797)$ and anemic patients $(N=119)$. PAC, pre-admission clinic

centre observational study reported $\mathrm{RBC}$ transfusion in $50 \%$ of anemic and $15 \%$ of non-anemic cardiac surgery patients [13]. A previous systematic review also revealed more anemic patients receiving $\mathrm{RBC}$ transfusion than non-anemic patients (33\% vs $12 \%$, respectively) [8]. Anemia has been established as a strong predictor of perioperative transfusion in cardiac surgery patients $[2$, 20-22]. Our study supports this observation and highlights the need for blood conservation in this patient population. In addition, we found no differences in the number of pRBC units transfused between anemic and non-anemic patients who required blood transfusion. A previous study, however, showed that patients with anemia received more units of RBCs compared to those without anemia [7]. The differences in sample sizes, patient populations and transfusion practices across different centres may explain these findings.

From our model, Hb concentration, eGFR, BSA, and total bypass time were found to be associated with transfusion on surgery day in cardiac surgery patients. Anemia is a known predictor of transfusion during surgery and the relationship has been well established in previous studies. The positive correlation between $\mathrm{CPB}$ time and risk of allogeneic blood transfusion has also been described in the literature [22-24]. Longer CPB time may lead to more inflammation, impaired hemostasis, increased fibrinolysis, and consequently increased blood loss and transfusion requirements. In addition, kidney function and BSA have been shown to be predictive of transfusion in cardiac surgery and both have been included in multiple risk score models to predict transfusion in cardiac surgery [25-28]. These findings support the validity of our model.
One of the goals of this study was to look into our preoperative intervention for anemic patients and identify any potential areas for improvement. Among anemic patients, $8 \%$ were referred to the blood conservation clinic and 3\% received treatment with iron therapy. Treatments were only initiated in moderate/severe anemic patients upon referral. Our elective cardiac surgery patients had a median of 7 days between their PAC visit and operation day, with the majority of patients having 7 days or less. Although patients were triaged based on their anemic status and available time for treatment prior to surgery, a typical course of treatment with iron therapy at our centre is at least 1 week, not taking into account referral, pre-treatment consultation, and treatment planning. This short window for preoperative correction of anemia explains why only a small percentage of our anemic patients got treated before their scheduled surgeries. Even though our cohort comprises of elective patients, cardiac surgery is often performed in a semi-acute setting where delaying surgery for preoperative anemia correction may carry more risk than benefit. The balance between anemia and transfusion risks versus the risks of delaying surgery needs to be taken into consideration, and evaluated on a case-tocase basis. It would be interesting to compare and contrast the time between initial visit and surgery day at other centres, as well as the effectiveness of their blood management program for elective cardiac surgery patients. In addition, patient referral to preoperative anemia correction was infrequently done, however, the reasons behind that remain to be determined.

Various preoperative blood management strategies have been studied such as iron therapy (oral and 
intravenous), erythropoietin administration, dietary supplements of vitamin B12 and folate, or preoperative autologous blood donation [15, 29, 30]. A recent singlecentre randomised controlled study found that a combination treatment of intravenous iron, subcutaneous erythropoietin alpha, vitamin B12, and oral folic acid on the day before surgery reduced $\mathrm{RBC}$ and total allogeneic blood product transfusions in patients with preoperative anemia or isolated iron deficiency undergoing elective cardiac surgery [31]. This is particularly relevant since it makes it possible to intervene in patients whose elective cardiac surgery is scheduled within a few days after an acute cardiac event.

The limitations of this study include all those of the single centre retrospective design. Our anemic patient sample size is also small, which may limit the generalizability of our findings. Health care provider preferences may affect the decision of whether or not to transfuse, as well as of how many pRBC units will be transfused in cases when a transfusion is decided. In addition, referral of anemic patients to the blood conservation clinic prior to surgery was not consistently done at our centre. The small number of anemic patients who got referred and treated made it difficult to assess the effectiveness of the blood conservation program at our centre. Other factors may influence the transfusion rates as well, but were not included in our study.

\section{Conclusions}

Preoperative anemia, defined using the WHO criteria, was present in $15 \%$ of our elective cardiac surgery patients with the majority of them classified as being mild or moderately anemic. Transfusion rate during surgery day was significantly higher at $53 \%$ in preoperative anemic patients compared to $10 \%$ in non-anemic patients. $\mathrm{Hb}$ concentration, eGFR, BSA, and total bypass time were found to be predictive of transfusion on surgery day among our elective cardiac surgery patients. Our patients had a median of 7 days between initial visit and surgery day. Referral to the blood management program and initiation of treatment were seldom done for anemic patients. A shift in the preoperative intervention pathway is needed at our centre to adequately correct anemia in anemic patients prior to surgery; however, this requires careful weighing of the risks of anemia and transfusion versus the risk of delaying surgery.

\section{Abbreviations}

AIC: Akaike information criterion; AUC: Area under the receiving operating characteristic curve; BMI: Body mass index; BSA: Body surface area; CABG: Coronary artery bypass graft; CBP: Cardiopulmonary bypass; Cls: Confidence intervals; CVA: Cerebrovascular accident; CVICU: Cardiovascular intensive care unit; DHCA: Deep hypothermic circulatory arrest; eGFR: estimated glomerular filtration rate; $\mathrm{Hb}$ : Hemoglobin; ICU: Intensive care unit; IQRs: Interquartile ranges; LVEF: Left ventricular ejection fraction; ORs: Odd ratios; PAC: Pre-admission clinic; pRBC: packed red blood cells; RBC: Red blood cell; WHO: World Health Organization

\section{Acknowledgements}

We thank all the patients who participated in this study

\section{Authors' contributions}

WL, EM and QN designed the project. JB, RB and WL supervised the work. QN and EM performed data acquisition. QN and WL performed data analysis and interpretation. QN wrote the manuscript. All authors read and approved the final manuscript.

\section{Funding}

None

\section{Availability of data and materials}

The datasets used and/or analysed during the current study are available from the corresponding author on reasonable request.

\section{Declarations}

Ethics approval and consent to participate

The study protocol was reviewed and approved by the Health Research Ethics Board at the University of Alberta, Edmonton, Canada (Pro00096889). Due to the retrospective design of the study, individual patient consent was waived.

\section{Consent for publication}

Not applicable.

\section{Competing interests}

The authors declare that they have no competing interests.

\section{Author details}

${ }^{1}$ Faculty of Medicine and Dentistry, University of Alberta, Edmonton, Canada. ${ }^{2}$ Division of Anesthesiology \& Pain Medicine, Department of Medicine, Faculty of Medicine and Dentistry, University of Alberta, Edmonton, Alberta T6G 2S2, Canada.

Received: 13 December 2020 Accepted: 9 April 2021

Published online: 23 April 2021

\section{References}

1. Loor G, Koch CG, Sabik JF, Li L, Blackstone EH. Implications and management of anemia in cardiac surgery: current state of knowledge. J Thorac Cardiovasc Surg 2012;144(3):538-546. Available from: https://doi. org/10.1016/j.jtcvs.2012.04.014

2. Hogan M, Klein AA, Richards T. The impact of anaemia and intravenous iron replacement therapy on outcomes in cardiac surgery. Eur J Cardio Thoracic Surg. 2014;47(2):218-26.

3. WHO. Haemoglobin concentrations for the diagnosis of anaemia and assessment of severity. In: Vitamin and Mineral Nutrition Information System. Geneva: World Healh Organ; 2011. Available from: http://scholar. google.com/scholar?hl=en\&btnG=Search\&q=intitle: Haemoglobin+ concentrations+for+the+diagnosis+of+anaemia+and+assessment+of+ severity\#1.

4. Karkouti K, Wijeysundera DN, Beattie WS. Risk associated with preoperative anemia in cardiac surgery : a multicenter cohort study. Circulation. 2008; 117(4):478-84. https://doi.org/10.1161/CIRCULATIONAHA.107.718353.

5. Karski JM, Mathieu M, Cheng D, Carroll J, Scott GJ. Etiology of preoperative anemia in patients undergoing scheduled cardiac surgery. Can J Anaesth. 1999;46(10):979-82. https://doi.org/10.1007/BF03013135.

6. Dai L, Mick SL, McCrae KR, Houghtaling PL, Sabik JF, Blackstone EH, et al. Preoperative Anemia in cardiac operation: does hemoglobin tell the whole story? Ann Thorac Surg 2018;105(1):100-107. Available from: https://doi. org/10.1016/j.athoracsur.2017.06.074, 2018.

7. Klein AA, Collier TJ, Brar MS, Evans C, Hallward G, Fletcher SN, et al. The incidence and importance of anaemia in patients undergoing cardiac surgery in the UK - the first Association of Cardiothoracic Anaesthetists national audit. Anaesthesia. 2016;71(6):627-35. https://doi.org/10.1111/ana e.13423. 
8. Padmanabhan H, Siau K, Curtis J, Ng A, Menon S, Luckraz H, et al. Preoperative Anemia and outcomes in cardiovascular surgery: systematic review and meta-analysis. Ann Thorac Surg 2019;108(6):1840-1848. Available from: https://doi.org/10.1016/j.athoracsur.2019.04.108.

9. Vlot EA, Verwijmeren L, Van De Garde EMW, Kloppenburg GTL, Van Dongen EPA, Noordzij PG. Intra-operative red blood cell transfusion and mortality after cardiac surgery. BMC Anesthesiol. 2019;19(1):1-7.

10. Lapar DJ, Hawkins RB, Mcmurry TL, Isbell M, Rich JB, Speir AM, et al. Preoperative anemia versus blood transfusion: which is the culprit for worse outcomes in cardiac surgery? J Thorac Cardiovasc Surg. 2019;156(1):66-74.

11. Tempe DK, Khurana P. Optimal blood transfusion practice in cardiac surgery. J Cardiothorac Vasc Anesth. 2018;32(6):2743-5. https://doi.org/10.1053/j. jvca.2018.05.051.

12. Padmanabhan H, Brookes MJ, Nevill AM, Luckraz H. Association between Anemia and blood transfusion with long-term mortality after cardiac surgery. Ann Thorac Surg 2019;108(3):687-692. Available from: https://doi. org/10.1016/j.athoracsur.2019.04.044, 2019.

13. von Heymann C, Kaufner L, Sander M, Spies C, Schmidt K, Gombotz H, Wernecke K.D., Balzer F. Does the severity of preoperative anemia or blood transfusion have a stronger impact on long-term survival after cardiac surgery? J Thorac Cardiovasc Surg 2016;152(5):1412-1420. Available from: https://doi.org/10.1016/j.jtcvs.2016.06.010

14. Karkouti K, Grocott HP, Hall R, Jessen ME, Kruger C, Lerner AB, et al. Interrelationship of preoperative anemia, intraoperative anemia, and red blood cell transfusion as potentially modifiable risk factors for acute kidney injury in cardiac surgery: a historical multicentre cohort study. Can J Anesth. 2015;62(4):377-84. https://doi.org/10.1007/s12630-014-0302-y.

15. Blaudszun G, Butchart A, Klein AA. Blood conservation in cardiac surgery. Transfus Med. 2018;28(2):168-80. https://doi.org/10.1111/tme.12475.

16. Raphael J, Mazer CD, Subramani S, Schroeder A, Abdalla M, Ferreira R, et al. Society of Cardiovascular Anesthesiologists Clinical Practice Improvement Advisory for Management of Perioperative Bleeding and Hemostasis in cardiac surgery patients. Anesth Analg. 2019;129(5):1209-21 Available from: http://www.ncbi.nlm.nih.gov/pubmed/31613811.

17. Society of Thoracic Surgeons Blood Conservation Guideline Task Force, Ferraris VA, Ferraris SP, Saha SP, Hessel EA, Haan CK, et al. Perioperative blood transfusion and blood conservation in cardiac surgery: the Society of Thoracic Surgeons and The Society of Cardiovascular Anesthesiologists clinical practice guideline. Ann Thorac Surg. 2007;83(5 Suppl):S27-86 Available from: http://www.ncbi.nlm.nih.gov/pubmed/17462454.

18. Task Force on Patient Blood Management for Adult Cardiac Surgery of the European Association for Cardio-Thoracic Surgery (EACTS) and the European Association of Cardiothoracic Anaesthesiology (EACTA), Boer C, Meesters MI, Milojevic M, Benedetto U, Bolliger D, et al. 2017 EACTS/EACTA Guidelines on patient blood management for adult cardiac surgery. J Cardiothorac Vasc Anesth. 2018;32(1):88-120 Available from: http://www.ncbi.nlm.nih.gov/ pubmed/29029990.

19. Carrascal Y, Maroto L, Rey J, Arévalo A, Arroyo J, Echevarría JR, et al. Impact of preoperative anemia on cardiac surgery in octogenarians. Interact Cardiovasc Thorac Surg. 2010;10(2):249-55 Available from: http://www.ncbi. nlm.nih.gov/pubmed/19889715.

20. Hung M, Besser M, Sharples LD, Nair SK, Klein AA. The prevalence and association with transfusion, intensive care unit stay and mortality of preoperative anaemia in a cohort of cardiac surgery patients. Anaesthesia. 2011;66(9):812-8 Available from: http://www.ncbi.nlm.nih.gov/pubmed/21 790520.

21. Ranucci M, Di Dedda U, Castelvecchio S, Menicanti L, Frigiola A, Pelissero G. Impact of preoperative anemia on outcome in adult cardiac surgery: a propensity-matched analysis. Ann Thorac Surg 2012;94(4):1134-1141. Available from: https://doi.org/10.1016/j.athoracsur.2012.04.042

22. Parr KG, Patel MA, Dekker R, Levin R, Glynn R, Avorn J, et al. Multivariate predictors of blood product use in cardiac surgery. J Cardiothorac Vasc Anesth. 2003;17(2):176-81 Available from: http://www.ncbi.nlm.nih.gov/ pubmed/12698398.

23. Koch CG, Li L, Duncan Al, Mihaljevic T, Cosgrove DM, Loop FD, et al. Morbidity and mortality risk associated with red blood cell and bloodcomponent transfusion in isolated coronary artery bypass grafting. Crit Care Med. 2006;34(6):1608-16 Available from: http://www.ncbi.nlm.nih.gov/ pubmed/16607235.

24. Litmathe J, Boeken U, Feindt P, Gams E. Predictors of homologous blood transfusion for patients undergoing open heart surgery. Thorac Cardiovasc
Surg. 2003;51(1):17-21 Available from: http://www.ncbi.nlm.nih.gov/ pubmed/12587083.

25. Klein AA, Collier T, Yeates J, Miles LF, Fletcher SN, Evans C, Richards T, Contributors The ACTA PORT-score for predicting perioperative risk of blood transfusion for adult cardiac surgery. Br J Anaesth 2017;119(3):394-401. Available from: https://doi.org/10.1093/bja/aex205

26. Goudie R, Sterne JAC, Verheyden V, Bhabra M, Ranucci M, Murphy GJ. Risk scores to facilitate preoperative prediction of transfusion and large volume blood transfusion associated with adult cardiac surgery. Br J Anaesth 2015; 114(5):757-766. Available from: https://doi.org/10.1093/bja/aeu483

27. Alghamdi AA, Davis A, Brister S, Corey P, Logan A. Development and validation of transfusion risk understanding scoring tool (TRUST) to stratify cardiac surgery patients according to their blood transfusion needs. Transfusion. 2006;46(7):1120-9. https://doi.org/10.1111/j.1537-2995.2006. 00860.x.

28. Karkouti K, Yau TM, Scott Beattie W, Callum J, Cheng D, Dupuis J-Y, et al. Prediction of massive blood transfusion in cardiac surgery. Can J Anesth. 2006;53(8):781-94. Available from: https://link-springer-com.myaccess.library. utoronto.ca/content/pdf/10.1007\%2FBF03022795.pdf. https://doi.org/10.1 007/BF03022795.

29. Dhir A, Tempe DK. Anemia and patient blood Management in Cardiac Surgery - Literature Review and Current Evidence. J Cardiothorac Vasc Anesth 2018;32(6):2726-2742. Available from: https://doi.org/10.1053/j.jvca.2 017.11 .043

30. Mueller MM, Van Remoortel H, Meybohm P, Aranko K, Aubron C, Burger R, et al. Patient blood management: recommendations from the 2018 Frankfurt consensus conference. JAMA. 2019;321(10):983-97. https://doi. org/10.1001/jama.2019.0554

31. Spahn DR, Schoenrath F, Spahn GH, Seifert B, Stein P, Theusinger OM, Kaserer A, Hegemann I, Hofmann A, Maisano F, Falk V Effect of ultra-shortterm treatment of patients with iron deficiency or anaemia undergoing cardiac surgery: a prospective randomised trial. Lancet 2019;393(10187): 2201-2212. Available from: https://doi.org/10.1016/S0140-6736(18)32555-8

\section{Publisher's Note}

Springer Nature remains neutral with regard to jurisdictional claims in published maps and institutional affiliations.

\section{Ready to submit your research? Choose BMC and benefit from:}

- fast, convenient online submission

- thorough peer review by experienced researchers in your field

- rapid publication on acceptance

- support for research data, including large and complex data types

- gold Open Access which fosters wider collaboration and increased citations

- maximum visibility for your research: over $100 \mathrm{M}$ website views per year

At $\mathrm{BMC}$, research is always in progress.

Learn more biomedcentral.com/submissions 